\author{
Ming Yueh Tan, Huey Chong Kwong, Karen A. Crouse, Thahira B.S.A. Ravoof \\ and Edward R.T. Tiekink*
}

\title{
Crystal structure of bis $\left\{\mathrm{N}\right.$-methyl- $\mathrm{N}^{\prime}$-[3-(4-methoxyphenyl)-1- methylpropane-1-ylidene]carbamohydrazonothioato\}zinc(II), $\mathrm{C}_{26} \mathrm{H}_{36} \mathrm{~N}_{6} \mathrm{O}_{2} \mathrm{~S}_{2} \mathrm{Zn}$
}

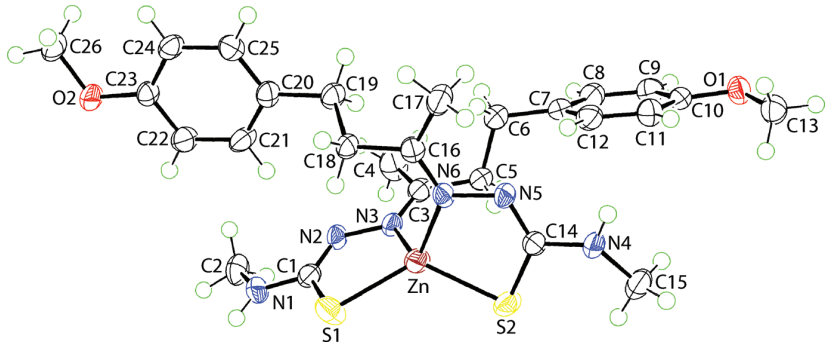

https://doi.org/10.1515/ncrs-2020-0381

Received July 21, 2020; accepted August 13, 2020; available online August 21, 2020

\section{Abstract}

$\mathrm{C}_{26} \mathrm{H}_{36} \mathrm{~N}_{6} \mathrm{O}_{2} \mathrm{~S}_{2} \mathrm{Zn}, \quad$ triclinic, $\quad P \overline{1} \quad$ (no. 2), $\quad a=9.1777(5) \AA$, $b=12.3828(7) \AA, \quad c=13.3137(7) \AA, \quad \alpha=102.157(5)^{\circ}$, $\beta=101.395(4)^{\circ}, \gamma=100.771(4)^{\circ}, V=1408.14(14) \AA^{3}, Z=2$, $R_{\mathrm{gt}}(F)=0.0489, w R_{\text {ref }}\left(F^{2}\right)=0.1147, T=100(2) \mathrm{K}$.

CCDC no.: 2023116

The molecular structure is shown in the figure. Table 1 contains crystallographic data and Table 2 contains the list of the atoms including atomic coordinates and displacement parameters.

\section{Source of material}

4-Methyl-3-thiosemicarbazide (Alfa Aesar), 4-(4methoxyphenyl)-2-butanone (Sigma Aldrich), zinc acetate dihydrate (Fluka), absolute ethanol (Merck) and acetonitrile

*Corresponding author: Edward R.T. Tiekink, Research Centre for Crystalline Materials, School of Science and Technology, Sunway University, 47500 Bandar Sunway, Selangor Darul Ehsan, Malaysia, e-mail: edwardt@sunway.edu.my. https://orcid.org/0000-00031401-1520

Ming Yueh Tan: Department of Physical Science, Faculty of Applied Sciences, Tunku Abdul Rahman University College, 50932 Setapak, Kuala Lumpur, Malaysia

Huey Chong Kwong: Research Centre for Crystalline Materials, School of Science and Technology, Sunway University, 47500

Bandar Sunway, Selangor Darul Ehsan, Malaysia

Karen A. Crouse and Thahira B.S.A. Ravoof: Department of Chemistry, Faculty of Science, Universiti Putra Malaysia, 43400 UPM Serdang, Selangor Darul Ehsan, Malaysia
Table 1: Data collection and handling.

\begin{tabular}{ll}
\hline Crystal: & Colourless slab \\
Size: & $0.16 \times 0.12 \times 0.04 \mathrm{~mm}$ \\
Wavelength: & Mo $K \alpha$ radiation $(0.71073 \AA$ A $)$ \\
$\mu:$ & $1.06 \mathrm{~mm}^{-1}$ \\
Diffractometer, scan mode: & Oxford Diffraction SuperNova, $\omega$ \\
$\theta_{\text {max }}$, completeness: & $28.8^{\circ},>99 \%$ \\
$N\left(h k l_{\text {measured }}, N(h k l)_{\text {unique }}, R_{\text {int }}:\right.$ & $12413,6335,0.041$ \\
Criterion for $I_{\text {obs }}, N(h k l)_{\mathrm{gt}}:$ & $I_{\text {obs }}>2 \sigma\left(I_{\text {obs }}\right), 4742$ \\
$N(\text { param })_{\text {refined }}:$ & 346 \\
Programs: & CrysAlis ${ }^{\text {PRO }}[1]$, SHELX [2, 3], \\
& WinGX/ORTEP [4] \\
\hline
\end{tabular}

Table 2: Fractional atomic coordinates and isotropic or equivalent isotropic displacement parameters $\left(\AA^{2}\right)$.

\begin{tabular}{lrrrr}
\hline Atom & $\boldsymbol{x}$ & $\boldsymbol{y}$ & $\boldsymbol{z}$ & $\boldsymbol{U}_{\text {iso }}{ }^{*} \boldsymbol{U}_{\text {eq }}$ \\
\hline Zn & $0.91082(4)$ & $0.22680(3)$ & $0.25162(3)$ & $0.02339(11)$ \\
S1 & $1.05901(9)$ & $0.21312(8)$ & $0.40419(6)$ & $0.0312(2)$ \\
S2 & $0.95685(9)$ & $0.17416(7)$ & $0.08882(6)$ & $0.02683(19)$ \\
O1 & $0.2828(2)$ & $0.17380(17)$ & $-0.33342(15)$ & $0.0252(5)$ \\
O2 & $0.7703(2)$ & $0.47250(17)$ & $0.85343(15)$ & $0.0241(5)$ \\
N1 & $0.9344(3)$ & $0.1265(2)$ & $0.54031(19)$ & $0.0246(6)$ \\
H1N & $1.0282(17)$ & $0.134(3)$ & $0.576(2)$ & $0.030^{*}$ \\
N2 & $0.7560(3)$ & $0.12345(19)$ & $0.39549(18)$ & $0.0200(5)$ \\
N3 & $0.7260(3)$ & $0.14303(19)$ & $0.29480(18)$ & $0.0198(5)$ \\
N4 & $0.8974(3)$ & $0.2964(2)$ & $-0.05031(19)$ & $0.0239(6)$ \\
H4N & $0.871(3)$ & $0.3557(17)$ & $-0.068(2)$ & $0.029^{*}$ \\
N5 & $0.8602(3)$ & $0.37436(19)$ & $0.10833(17)$ & $0.0189(5)$ \\
N6 & $0.8690(3)$ & $0.3710(2)$ & $0.21359(17)$ & $0.0184(5)$ \\
C1 & $0.9009(3)$ & $0.1484(2)$ & $0.4448(2)$ & $0.0226(6)$ \\
C2 & $0.8186(4)$ & $0.0648(3)$ & $0.5811(2)$ & $0.0284(7)$ \\
H2A & 0.749031 & 0.112787 & 0.599245 & $0.043^{*}$ \\
H2B & 0.867998 & 0.044831 & 0.644554 & $0.043^{*}$ \\
H2C & 0.760462 & -0.004687 & 0.526930 & $0.043^{*}$ \\
C3 & $0.5837(3)$ & $0.1119(2)$ & $0.2430(2)$ & $0.0222(6)$ \\
C4 & $0.4595(4)$ & $0.0630(3)$ & $0.2906(3)$ & $0.0347(8)$ \\
H4A & 0.472653 & -0.010555 & 0.302092 & $0.052^{*}$ \\
H4B & 0.359474 & 0.052462 & 0.242217 & $0.052^{*}$ \\
H4C & 0.465267 & 0.115213 & 0.358513 & $0.052^{*}$ \\
C5 & $0.5419(3)$ & $0.1171(2)$ & $0.1300(2)$ & $0.0223(6)$ \\
H5A & 0.484133 & 0.040520 & 0.085944 & $0.027^{*}$ \\
H5B & 0.637342 & 0.136505 & 0.106805 & $0.027^{*}$ \\
C6 & $0.4458(3)$ & $0.2031(3)$ & $0.1083(2)$ & $0.0253(7)$ \\
H6A & 0.351607 & 0.186403 & 0.133502 & $0.030^{*}$ \\
H6B & 0.505016 & 0.280821 & 0.148396 & $0.030^{*}$ \\
C7 & $0.4030(3)$ & $0.1981(2)$ & $-0.0083(2)$ & $0.0225(6)$ \\
& & & &
\end{tabular}

ð Open Access. @ 2020 Ming Yueh Tan et al., published by De Gruyter. (ल) BY This work is licensed under the Creative Commons Attribution 4.0 International License. 
Table 2 (continued)

\begin{tabular}{|c|c|c|c|c|}
\hline Atom & $x$ & $y$ & $z$ & $U_{\text {iso }} * / U_{\text {eq }}$ \\
\hline $\mathrm{C} 8$ & $0.2708(3)$ & $0.1227(3)$ & $-0.0763(2)$ & $0.0257(7)$ \\
\hline $\mathrm{H} 8$ & 0.204348 & 0.075593 & -0.048087 & $0.031^{\star}$ \\
\hline C9 & $0.2344(3)$ & $0.1153(2)$ & $-0.1840(2)$ & $0.0245(7)$ \\
\hline H9 & 0.143864 & 0.063324 & -0.228777 & $0.029^{\star}$ \\
\hline C10 & $0.3300(3)$ & $0.1836(2)$ & $-0.2266(2)$ & $0.0207(6)$ \\
\hline C11 & $0.4633(3)$ & $0.2585(2)$ & $-0.1605(2)$ & $0.0235(6)$ \\
\hline H11 & 0.530362 & 0.304856 & -0.188890 & $0.028^{\star}$ \\
\hline C12 & $0.4976(3)$ & $0.2648(3)$ & $-0.0531(2)$ & $0.0250(7)$ \\
\hline H12 & 0.588541 & 0.316373 & -0.008467 & 0.030 * \\
\hline C13 & $0.3930(4)$ & $0.2258(3)$ & $-0.3822(2)$ & $0.0291(7)$ \\
\hline $\mathrm{H} 13 \mathrm{~A}$ & 0.419644 & 0.308402 & -0.352819 & $0.044^{\star}$ \\
\hline H13B & 0.349675 & 0.207772 & -0.458899 & $0.044^{\star}$ \\
\hline $\mathrm{H} 13 \mathrm{C}$ & 0.485239 & 0.196625 & -0.368383 & $0.044^{\star}$ \\
\hline C14 & $0.8999(3)$ & $0.2903(2)$ & $0.0509(2)$ & $0.0201(6)$ \\
\hline C15 & $0.9007(4)$ & $0.2041(3)$ & $-0.1360(2)$ & $0.0348(8)$ \\
\hline H15A & 0.938601 & 0.145388 & -0.106882 & $0.052^{\star}$ \\
\hline H15B & 0.968623 & 0.232906 & -0.177710 & $0.052^{\star}$ \\
\hline $\mathrm{H} 15 \mathrm{C}$ & 0.797169 & 0.171425 & -0.181665 & $0.052^{\star}$ \\
\hline C16 & $0.8408(3)$ & $0.4583(2)$ & $0.2724(2)$ & $0.0201(6)$ \\
\hline C17 & $0.8037(4)$ & $0.5563(3)$ & $0.2320(2)$ & $0.0280(7)$ \\
\hline H17A & 0.875540 & 0.578981 & 0.190441 & $0.042^{\star}$ \\
\hline H17B & 0.812110 & 0.620418 & 0.292006 & $0.042^{\star}$ \\
\hline $\mathrm{H} 17 \mathrm{C}$ & 0.699046 & 0.533705 & 0.187045 & $0.042^{\star}$ \\
\hline C18 & $0.8486(3)$ & $0.4620(3)$ & $0.3864(2)$ & $0.0213(6)$ \\
\hline H18A & 0.917021 & 0.535177 & 0.430815 & $0.026^{\star}$ \\
\hline H18B & 0.894879 & 0.400237 & 0.404305 & $0.026^{\star}$ \\
\hline C19 & $0.6920(3)$ & $0.4494(3)$ & $0.4144(2)$ & $0.0236(6)$ \\
\hline H19A & 0.643699 & 0.509777 & 0.395146 & $0.028^{\star}$ \\
\hline H19B & 0.624222 & 0.374943 & 0.372579 & $0.028^{\star}$ \\
\hline C20 & $0.7088(3)$ & $0.4578(2)$ & $0.5309(2)$ & $0.0212(6)$ \\
\hline C21 & $0.7537(3)$ & $0.3734(3)$ & $0.5749(2)$ & $0.0258(7)$ \\
\hline $\mathrm{H} 21$ & 0.770734 & 0.308709 & 0.530142 & $0.031^{\star}$ \\
\hline C22 & $0.7742(3)$ & $0.3810(3)$ & $0.6817(2)$ & $0.0255(7)$ \\
\hline H22 & 0.805331 & 0.321999 & 0.709504 & $0.031^{\star}$ \\
\hline C23 & $0.7495(3)$ & $0.4744(2)$ & $0.7491(2)$ & $0.0193(6)$ \\
\hline C24 & $0.7044(3)$ & $0.5595(3)$ & $0.7070(2)$ & $0.0227(6)$ \\
\hline $\mathrm{H} 24$ & 0.686532 & 0.623728 & 0.751709 & $0.027^{\star}$ \\
\hline C25 & $0.6853(3)$ & $0.5506(2)$ & $0.5986(2)$ & $0.0223(6)$ \\
\hline $\mathrm{H} 25$ & 0.655293 & 0.609832 & 0.570664 & $0.027^{\star}$ \\
\hline C26 & $0.7232(4)$ & $0.5576(3)$ & $0.9225(2)$ & $0.0270(7)$ \\
\hline $\mathrm{H} 26 \mathrm{~A}$ & 0.783559 & 0.633148 & 0.926034 & $0.040^{\star}$ \\
\hline H26B & 0.739633 & 0.544784 & 0.993571 & $0.040^{\star}$ \\
\hline $\mathrm{H} 26 \mathrm{C}$ & 0.614448 & 0.553090 & 0.894898 & $0.040^{\star}$ \\
\hline
\end{tabular}

(Merck) were of analytical grade and used as purchased. The Schiff base ligand, LH, was prepared as described in the literature [5]. Zinc acetate dihydrate $(0.220 \mathrm{~g}, 10 \mathrm{mmol})$ was dissolved in hot ethanol $(20 \mathrm{~mL})$ and added to a solution of LH (0.530 g, $20 \mathrm{mmol})$ in hot absolute ethanol $(20 \mathrm{~mL})$ while stirring for $30 \mathrm{~min}$. The white precipitate was filtered, washed with cold ethanol and dried in vacuo. Single crystals were grown at room temperature from the slow evaporation of an acetonitrile/absolute ethanol (2:1 v/v) solution. Yield: 89\%. M. Pt: 434-435 K. FT-IR (ATR (solid) $\mathrm{cm}^{-1}$ ): 3366 $v(\mathrm{~N}-\mathrm{H}), 1606 \mathrm{v}(\mathrm{C}=\mathrm{N}), 1239 \mathrm{v}(\mathrm{N}-\mathrm{N}), 516 \mathrm{v}(\mathrm{Zn}-\mathrm{N}), 439 v(\mathrm{Zn}-$ S). UV-Visible: $\lambda_{\max }\left(\mathrm{nm} ; \epsilon\left(\mathrm{L} \mathrm{mol}^{-1} \mathrm{~cm}^{-1}\right)\right)$ : 239 (76,913),
279 (51,641). ICP-AES: Experimental \% $\mathrm{Zn}=11.05$, Theoretical $\% \mathrm{Zn}=11.00$.

\section{Experimental details}

The $\mathrm{C}$-bound $\mathrm{H}$ atoms were geometrically placed $(\mathrm{C}-\mathrm{H}=$ 0.95-0.99 $\AA$ ) and refined as riding with $U_{\text {iso }}(\mathrm{H})=1.2-$ $1.5 U_{\text {eq }}(\mathrm{C})$. The $\mathrm{N}$-bound $\mathrm{H}$ atoms were refined with $\mathrm{N}-\mathrm{H}=0.88 \pm 0.01 \AA$, and with $U_{\text {iso }}(\mathrm{H})=1.2 U_{\text {eq }}(\mathrm{N})$.

\section{Comment}

Metal complexes derived from thiosemicarbazones, $\mathrm{R}^{1} \mathrm{R}^{2} \mathrm{C}=\mathrm{N}-\mathrm{N}\left(\mathrm{R}^{3}\right)-\mathrm{C}(=\mathrm{S}) \mathrm{NR}^{4} \mathrm{R}^{5}$, for $\mathrm{R}^{1-5}=\mathrm{H} /$ alkyl/aryl have huge potential variability in composition and many are well-documented as having therapeutic applications and for their use as imaging agents [6]. Among the former, zinc(II) complexes are prominent with reports of their potential as anti-bacterial [7], anti-cancer [8] and antiviral [9] agents. In continuation of biological studies of different metal complexes of thiosemicarbazones [10] and of supporting structural studies of zinc thiosemicarbazones [11, 12], herein the synthesis, characterisation as well as the crystal and molecular structures of $\mathrm{Zn}\left[\left(4-\mathrm{MeOC}_{6} \mathrm{H}_{4}\right) \mathrm{CH}_{2} \mathrm{CH}_{2} \mathrm{C}(\mathrm{Me})=\mathrm{NN}=\mathrm{C}(\mathrm{S}) \mathrm{N}(\mathrm{H}) \mathrm{Me}\right]_{2}$, (I), are described.

The molecular structure of (I) is shown in the figure (70\% displacement ellipsoids) which shows the zinc(II) centre to be bis-chelated in a N,S-fashion by two monoanionic thiosemicarbazato ligands. For the S1-ligand, the ZnS1 [2.2680(9) $\AA]$ and $\mathrm{Zn}-\mathrm{N} 3$ [2.065(2) $\AA$ ] bond lengths are shorter and longer, respectively, than the equivalent $\mathrm{Zn}-\mathrm{S} 2$

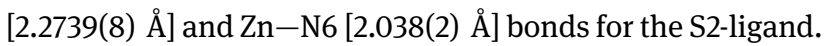
Compared with the structure of the uncoordinated ligand [5], the $\mathrm{C}-\mathrm{S}[\mathrm{C} 1-\mathrm{S} 1=1.760(3) \AA$ and $\mathrm{C} 14-\mathrm{S} 2=1.755(3) \AA]$ and $[\mathrm{C} 1=\mathrm{N} 2=1.308(4) \AA$ and $\mathrm{C} 14=\mathrm{N} 5=1.310(3) \AA]$ bond lengths in (I) have elongated and shortened, respectively, compared with the $\mathrm{C} 1=\mathrm{S} 1$ [1.6943(13) \& 1.6881(13) $\AA$ for the two independent molecules] and C1-N2 [1.3563(17) \& 1.3616(17) $\AA$ ] bond lengths of the acid, confirming the newly formed thiolate and imine bonds in (I) (see the figure).

The $\mathrm{N}_{2} \mathrm{~S}_{2}$ at $\mathrm{Zn}$ donor set defines an approximate tetrahedral geometry with the range of angles being $87.10(7)^{\circ}$ for the $\mathrm{S} 1-\mathrm{Zn}-\mathrm{N} 3$ chelate angle to $127.45(7)^{\circ}$ for $\mathrm{S} 1-\mathrm{Zn}-\mathrm{N} 6$. The mode of coordination of the ligands leads to the formation of five-membered chelate rings. These are best described as having an envelope conformation with Zn lying 0.131(4) Å out of the least-squares plane defined by the remaining four atoms [r.m.s. deviation $=0.018 \AA$ ] for the S1-ligand. The envelope description is more pronounced for the S2-ligand with the equivalent parameters being $0.229(4)$ and $0.006 \AA$, respectively. The dihedral angle formed between the best planes through the rings is $79.95(5)^{\circ}$. 
As discussed recently [11], are now more than ten known mononuclear complexes described by the general formula $\mathrm{Zn}\left[\mathrm{SC}\left(\mathrm{NHR}^{4}\right)=\mathrm{NNCR}^{1} \mathrm{R}^{2}\right]_{2}$ where the R groups are noncoordinating and which crystallise solvent-free. To a first approximation, each of these structures resembles (I) but, with varying degrees of distortion from the ideal tetrahedral geometry evident, as manifested in the dihedral angle between the chelate rings. The chelate/chelate angles in the literature structures vary from $60.10(5)$ to $89.65(5)^{\circ}$. Interestingly, these angles are calculated for the two independent molecules in the asymmetric unit of the complex with $\mathrm{R}^{1}=\mathrm{R}^{4}=\mathrm{Ph}$ and $\mathrm{R}^{2}=\mathrm{Me}$ [13], suggesting an influence of molecular packing effects on the adopted conformation.

In the crystal of (I), thioamide- $\mathrm{N}-\mathrm{H} \cdots \mathrm{O}$ (methoxy) hydrogen bonds $\left[\mathrm{N} 1-\mathrm{H} 1 \mathrm{n} \cdots \mathrm{O} 1^{\mathrm{i}}: \quad \mathrm{H} 1 \mathrm{n} \cdots \mathrm{O} 1^{\mathrm{i}}=2.32(2) \AA\right.$, $\mathrm{N} 1 \cdots O 1^{\mathrm{i}}=3.187(3) \AA$ with angle at $\mathrm{H} 1 \mathrm{n}=174(3)^{\circ}$ and $\mathrm{N} 4-$ $\mathrm{H} 4 \mathrm{n} \cdots \mathrm{O} 2^{\mathrm{ii}}: \mathrm{H} 4 \mathrm{n} \cdots \mathrm{O} 2^{\mathrm{ii}}=2.19(2) \AA$, N4 $\cdots \mathrm{O} 2^{\mathrm{ii}}=3.049(3) \AA$ with angle at $\mathrm{H} 4 \mathrm{n}=166(2)^{\circ}$ for symmetry operations (i) $1+x, y, 1+z$ and (ii) $x, y,-1+z]$ are formed and lead to supramolecular layers perpendicular to [0 10$]$. In accord with the distance criteria in PLATON [14], no further directional interactions are apparent. Globally, centrosymmetrically related layers assemble into double-layers and inter-digitate along the $b$-axis.

A further analysis of the molecular packing was performed utilising Crystal Explorer 17 [15] and calculating the Hirshfeld surface and two-dimensional fingerprint plots (full and delineated) following literature procedures [16]. Consistent with the above description of the molecular packing, $\mathrm{H} \cdots \mathrm{H}$ contacts contribute $59.8 \%$ of all contacts to the surface. The most striking feature of the fingerprint plots are the well-defined spikes owing to the $\mathrm{N}-\mathrm{H} \cdots \mathrm{O}$ hydrogen bonding. However, all $\mathrm{H} \cdots \mathrm{O} / \mathrm{O} \cdots \mathrm{H}$ contacts contribute only $6.5 \%$ to the overall Hirshfeld surface. More prominent are $\mathrm{H} \cdots \mathrm{C} / \mathrm{C} \cdots \mathrm{H}[14.3 \%]$ and $\mathrm{H} \cdots \mathrm{S} / \mathrm{S} \cdots \mathrm{S}[11.9 \%]$ contacts; $\mathrm{H} \cdots \mathrm{N} / \mathrm{N} \cdots \mathrm{H}[2.7 \%]$ contacts make only a minor contribution.

Acknowledgements: The X-ray intensity data were collected by Mohamed I. M. Tahir, Universiti Putra Malaysia. The synthetic part of this research was supported by the Research University Grant Scheme (RUGS Nos. 9199834 and 9174000) and the Malaysian Ministry of Science, Technology and Innovation (Grant No. 09-02-04-0752-EA001). Sunway University Sdn Bhd is thanked for financial support of this work through Grant No. STR-RCTR-RCCM-001-2019.

\section{References}

1. Agilent Technologies. CrysAlis ${ }^{\mathrm{PRO}}$. Agilent Technologies, Santa Clara, CA, USA (2012).
2. Sheldrick, G. M.: A short history of SHELX. Acta Crystallogr. A64 (2008) 112-122.

3. Sheldrick, G. M.: Crystal structure refinement with SHELXL. Acta Crystallogr. C71 (2015) 3-8.

4. Farrugia, L. J.: WinGX and ORTEP for Windows: an update. J. Appl. Cryst. 45 (2012) 849-854.

5. Tan, M.-Y.; Ravoof, T. B. S. A.; Tahir, M. I. M.; Crouse, K. A.; Tiekink, E. R. T.: 1-\{(E)-[4-(4-Methoxyphenyl)butan-2-ylidene] amino\}-3-methylthiourea. Acta Crystallogr. E68 (2012) 01461-01462.

6. Dilworth, J. R.; Hueting, R.: Metal complexes of thiosemicarbazones for imaging and therapy. Inorg. Chim. Acta 389 (2012) 3-15.

7. Afrasiabi, Z.; Sinn, E.; Padhye, S.; Dutta, S.; Padhye, S.; Newton, C.; Anson, C. E.; Powell, A. K.: Transition metal complexes of phenanthrenequinone thiosemicarbazone as potential anticancer agents: synthesis, structure, spectroscopy, electrochemistry and in vitro anticancer activity against human breast cancer cell-line, T47D. J. Inorg. Biochem. 95 (2003) 306-314.

8. Quiroga, A. G.; Ranninger, C. N.: Contribution to the SAR field of metallated and coordination complexes: studies of the palladium and platinum derivatives with selected thiosemicarbazones as antitumoral drugs. Coord. Chem. Rev. 248 (2004) 119-133.

9. Garoufis, A.; Hadjikakou, S. K.; Hadjiliadis, N.: Palladium coordination compounds as anti-viral, anti-fungal, antimicrobial and anti-tumor agents. Coord. Chem. Rev. 253 (2009) 1384-1397.

10. Saswati,; Adão, P.; Majumder, S.; Dash, S. P.; Roy, S.; Kuznetsov, M. L.; Costa Pessoa, J.; Gomes, C. S. B.; Hardikar, M. R.; Tiekink, E. R. T.; Dinda, R.: Synthesis, structure, solution behavior, reactivity and biological evaluation of oxidovanadium(IV/V) thiosemicarbazone complexes. Dalton Trans. 47 (2018) 11358-11374.

11. Tan, M. Y.; Crouse, K. A.; Ravoof, T. B. S. A.; Jotani, M. M.; Tiekink, E. R. T.: $\operatorname{Bis}\left(N^{\prime}-\{(E)-[(2 E)-1,3-d i p h e n y l p r o p-2-e n-1-\right.$ ylidene]amino\}- $N$-ethylcarbamimidothioato- ${ }^{2} N, S$ )zinc(II): crystal structure and Hirshfeld surface analysis. Acta Crystallogr. E73 (2017) 1001-1008.

12. Tan, M. Y.; Crouse, K. A.; Ravoof, T. B. S. A.; Jotani, M. M.; Tiekink, E. R. T.: Bis(4-methoxychalcone 4-ethylthiosemicarbazonato- $\left.\mathrm{K}^{2} N^{\prime}, S\right)$ zinc(II): crystal structure and Hirshfeld surface analysis. Acta Crystallogr. E74 (2018) 151-157.

13. Wang, H.; Zhao, P.; Shao, D.; Zhang, J.; Zhu, Y.: Synthesis, characterization and spectra studies on $\mathrm{Zn}$ (II) and $\mathrm{Cu}$ (II) complexes with thiocarbamide ligand containing Schiff base group. Struct. Chem. 20 (2009) article no. 995.

14. Spek, A. L.: CheckCIF validation ALERTS: what they mean and how to respond. Acta Crystallogr. E76 (2020) 1-11.

15. Turner, M. J.; McKinnon, J. J.; Wolff, S. K.; Grimwood, D. J.; Spackman, P. R.; Jayatilaka, D.; Spackman, M. A.: Crystal Explorer v17. The University of Western Australia, Australia (2017).

16. Tan, S. L.; Jotani, M. M.; Tiekink, E. R. T.: Utilizing Hirshfeld surface calculations, non-covalent interaction $(\mathrm{NCl})$ plots and the calculation of interaction energies in the analysis of molecular packing. Acta Crystallogr. E75 (2019) 308-318. 